\title{
AEROSOL ABSORPTION PROFILING FROM THE SYNERGY OF LIDAR AND SUN- PHOTOMETRY: THE ACTRIS-2 CAMPAIGNS IN GERMANY, GREECE AND CYPRUS
}

Alexandra Tsekeri $^{{ }^{*} \text {, }}$ Vassilis Amiridis ${ }^{1}$, Anton Lopatin ${ }^{2}$, Eleni Marinou ${ }^{1,3}$, Eleni Giannakaki ${ }^{4,5}$, Michael Pikridas $^{6}$, Jean Sciare ${ }^{6}$, Eleni Liakakou ${ }^{7}$, Evangelos Gerasopoulos ${ }^{7}$, Sebastian Duesing ${ }^{8}$, Joel C. Corbin', Martin Gysel', Nicolas Bukowiecki ${ }^{9}$, Holger Baars ${ }^{8}$, Ronny Engelmann ${ }^{8}$, Birgit Wehner $^{8}$, Michael Kottas ${ }^{1}$, Dimitra Mamali ${ }^{10}$, Panagiotis Kokkalis ${ }^{1}$, Panagiotis I. Raptis ${ }^{7}$, Iasonas Stavroulas $^{6}$, Christos Keleshis ${ }^{6}$, Detlef Müller ${ }^{11}$, Stavros Solomos ${ }^{1}$, Ioannis Binietoglou ${ }^{1,12}$, Nikolaos Mihalopoulos $^{7}$, Alexandros Papayannis ${ }^{13}$, Iwona S. Stachlewska ${ }^{14}$, Julia Igloffstein ${ }^{8}$, Ulla Wandinger $^{8}$, Albert Ansmann ${ }^{8}$, Oleg Dubovik ${ }^{2}$, Philippe Goloub ${ }^{2}$

${ }^{I}$ Institute for Astronomy Astrophysics Space Applications and Remote Sensing, National Observatory of Athens, Athens, Greece, *atsekeri@noa.gr

${ }^{2}$ Laboratoire d'Optique Atmosphérique, Université de Lille, Lille, France

${ }^{3}$ Laboratory of Atmospheric Physics, Department of Physics, Aristotle University of Thessaloniki, Thessaloniki, Greece

${ }^{4}$ Finnish Meteorological Institute, Kuopio, Finland

${ }^{5}$ Department of Environmental Physics and Meteorology, Faculty of Physics, University of Athens, Athens, Greece

${ }^{6}$ The Cyprus Institute, Environment Energy and Water Research Center, Nicosia, Cyprus

${ }^{7}$ Institute for Environmental Research and Sustainable Development, National Observatory of Athens, Athens, Greece

${ }^{8}$ Leibniz Institute for Tropospheric Research, Leipzig, Germany

${ }^{9}$ Laboratory of Atmospheric Chemistry, Paul Scherrer Institute, Villigen, Switzerland

${ }^{10}$ Faculty of Civil Engineering and Geosciences, Delft University of Technology, Delft, The Netherlands

${ }^{11}$ School of Physics, Astronomy and Mathematics, University of Hertfordshire, Hatfield, UK

${ }_{12}$ National Institute of $R \& D$ for Optoelectronics, Magurele, Ilfov, Romania

${ }^{13}$ Physics Department, National Technical University of Athens, Athens, Greece

${ }^{14}$ Institute of Geophysics, Faculty of Physics, University of Warsaw, Warsaw, Poland

\begin{abstract}
Aerosol absorption profiling is crucial for radiative transfer calculations and climate modelling. Here, we utilize the synergy of lidar with sun-photometer measurements to derive the absorption coefficient and single scattering albedo profiles during the ACTRIS-2 campaigns held in Germany, Greece and Cyprus. The remote sensing techniques are compared with in situ measurements in order to harmonize and validate the different methodologies and reduce the absorption profiling uncertainties.
\end{abstract}

\section{INTRODUCTION}

Absorption is a key climate-relevant aerosol property of particular importance for aerosolradiation and aerosol-cloud interactions. Specifically, aerosol absorption can directly modify the global radiation budget, indirectly modify cloud properties and abundance (e.g. [1]) and thus modify the atmospheric stability in the boundary layer and free troposphere (e.g. [2]). However, the magnitude of absorption at the global scale is subject to considerable uncertainties, for aerosol particles of both anthropogenic and natural origin. While the aerosol optical depth (AOD) and aerosol particle size distribution are relatively well-constrained from measurements, uncertainties related to the SSA (e.g. [3]), and especially the vertical profile of the black carbon (BC) concentration, which is the main light-absorbing component in the visible wavelength range, contribute significantly to the overall uncertainties of the aerosol radiative effect.

The European project Aerosols, Clouds and Trace gases Research Infrastructure (ACTRIS-2 
http://www.actris.eu) through its Joint Research Activity 1 (JRA1) focuses on reducing the uncertainty in the determination of the aerosol light absorption vertical profiles by combining and optimizing advanced remote sensing and in situ methods. The novel remote sensing and in situ instrumentation included in the ACTRIS research infrastructure, offers a unique opportunity for a comprehensive absorption characterization of anthropogenic and natural aerosols, within urban and remote sites of the network in Europe. The vertical distribution of the absorption coefficient and the SSA are retrieved via surface and airborne in situ measurements and remote sensing techniques, and dedicated ACTRIS JRA1 campaigns have been organized to perform closure studies between these different methods. Here we present results from the campaigns in Melpitz, Germany (May-June 2015), in Athens, Greece (December 2015 February 2016) and in Nicosia/Agia Marina/Orounda, Cyprus (May-June 2016).

\section{METHODOLOGY}

The remote sensing retrieval of the absorption vertical structure is performed with the synergy of passive and active remote sensing instruments, i.e. multiwavelength lidars and sun-photometers. The sun-photometer provides the columnar properties of the particles (e.g. [4]), whereas lidars are capable of providing vertically resolved profiles of the backscatter and extinction coefficients, along with vertical profiles of the particle microphysical properties, mainly for the fine mode (e.g. [5]). The Generalized Aerosol Retrieval from Radiometer and Lidar Combined data algorithm (GARRLiC [6]), developed in the framework of ACTRIS, goes a step further using for the first time both sun-photometer and lidar measurements in the combined retrieval of the particle microphysical properties. Figure 1 shows the algorithm's input and output.

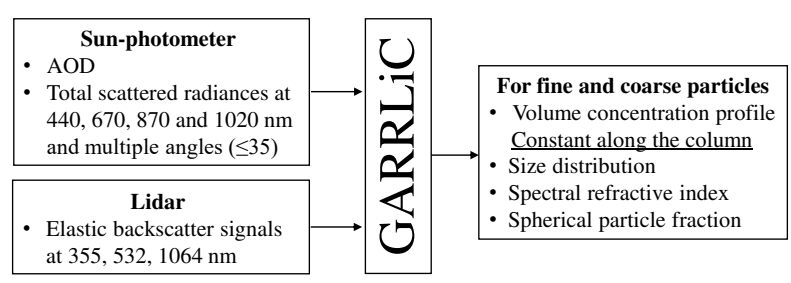

Figure 1 The GARRLiC algorithm input and output parameters

During the ACTRIS-2 JRA1 campaigns, intensive ground-based active and passive remote sensing measurements were performed with Polly ${ }^{\mathrm{XT}}$ lidars and CIMEL sun-photometers. Both GARRLiC and the lidar stand-alone algorithm of Müller et al. [5] are used to produce the absorption coefficient and SSA vertical profiles. The lidar stand-alone algorithm is very useful for days with broken or high clouds, when the GARRLiC retrieval cannot be applied due to the lack of sun-photometer measurements.

For the in situ measurements of the absorption profile airborne platforms were deployed, to acquire the absorption and scattering coefficients, BC mass concentration and particle size with multi-wavelength aethalometers, nephelometers, and optical particle sizers, respectively. More specifically, in the framework of the Athens and Cyprus campaigns, a new light-weight absorption monitor, named Dual Wavelength Prototype (DWP), was used onboard unmanned aerial vehicles (UAVs), providing the absorption coefficient at 370 and $880 \mathrm{~nm}$. In the Melpitz campaign, the Airborne Cloud Turbulence Observation System (ACTOS), carried by a helicopter, acquired absorption measurements with a $630 \mathrm{~nm}$ CAPS-PMssa monitor (Aerodyne, USA) [7]. This instrument performs calibrationfree extinction coefficient measurements (with 5\% accuracy). Scattering coefficients are measured from the same optical cavity via integrating nephelometry. In situ absorption (extinction minus scattering) is thus obtained, with greatest accuracy for low SSA environments. ACTOS also carried a Single channel Tri-color Absorption Photometer (STAP, Brechtel, Hayward, CA 94544), measuring the particle absorption at 450,525 and $624 \mathrm{~nm}$.

\section{RESULTS}

The comparison of remote sensing retrievals of the absorption coefficient with the airborne and surface in situ measurements during the ACTRIS JRA1 campaigns in Melpitz, Athens and Cyprus are shown in Fig. 2. 


\subsection{Melpitz campaign}

During the Melpitz campaign the particle extinction coefficient was low, with AODs at 440 $\mathrm{nm}$ not exceeding the value of 0.2 , and the SSA was generally above 0.9 , with correspondingly low absorption coefficients. This means that signal-to-noise ratios for in situ and remote sensing measurements were the lowest for this campaign. Although the AOD requirements have not been quantified yet for GARRLiC, an AOD of 0.3 at $440 \mathrm{~nm}$ is considered sufficient for the SSA retrieval.
For the case of 24 June the AOD at $440 \mathrm{~nm}$ was 0.14. The GARRLiC results show large uncertainties $\left(\sim 7 \mathrm{Mm}^{-1}\right)$, but they have similar slopes with the in situ absorption profiles, although they produce larger values (left plots in Fig. 2a). The lidar stand-alone retrieval has comparably large uncertainty for the case of 17 June, with an AOD at $440 \mathrm{~nm}$ of 0.17 (right plots in Fig. 2a). In part due to the large uncertainties, the in-situ and remote sensing results are not statistically different for this case, although the latter have larger values.
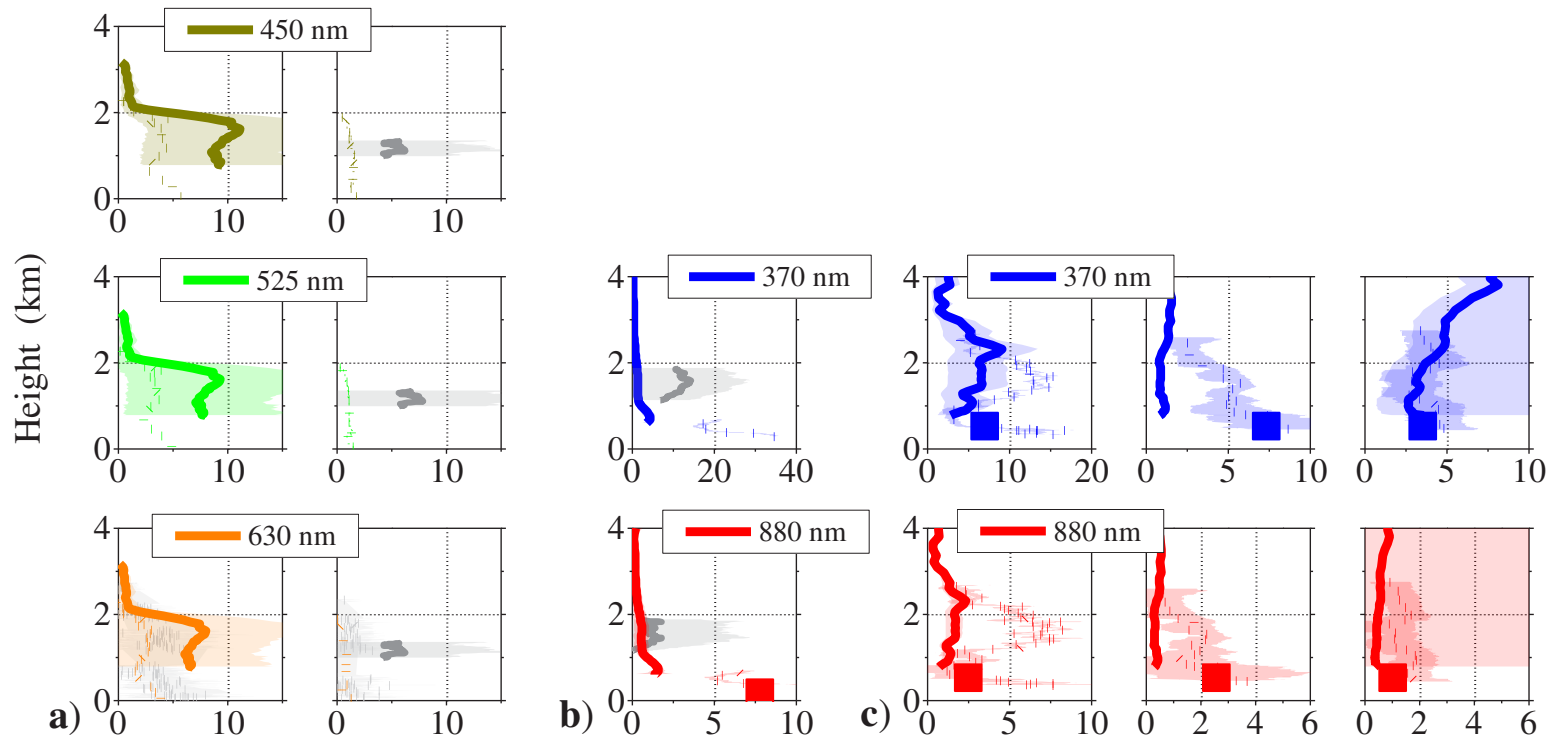

Absorption coefficient $\left(\mathrm{Mm}^{-1}\right)$

Figure 2 Absorption coefficient profiles retrieved from remote sensing measurements, from GARRLiC (colored solid lines) and lidar stand-alone algorithms (grey solid lines), and measured with airborne platforms with in situ instruments, i.e. CAPS-PMssa monitor (grey dash line) and STAP (colored dash lines) for Melpitz campaign, and the DWP (colored dashed lines) for Athens and Cyprus campaigns. The surface in situ measurements are denoted with squares. The absorption coefficients are provided at 370, 450, 525, 630 and $880 \mathrm{~nm}$. The results are from the ACTRIS-2 JRA1 campaigns in: a) Melpitz, Germany, on 24 and 17 June 2015, b) Athens, Greece, on 19 January 2016 and c) Nicosia, Cyprus, on 7, 15 and 21 April 2016.

\subsection{Athens campaign}

During the Athens campaign there were few cloud-free days available to use for the combined lidar/sun-photometer GARRLiC retrieval and the AODs were low $(<0.2$ at $440 \mathrm{~nm})$. Another challenge for the remote sensing retrievals is that most of the aerosol were located below $\sim 1 \mathrm{~km}$, in the lidar incomplete overlap region. In this region, there is large uncertainty in the lidar backscattered signal, which is only partially collected from the telescope [8]. We are currently working on enhancing the information in this region by utilizing the near-range measurements of the Polly ${ }^{\mathrm{XT}}$ lidar, performing the signal gluing technique. Due to the low flight heights of the UAVs (up to $700 \mathrm{~m}$ a.g.l. for the case shown here), the retrieved profiles do not overlap. In the results of 19 January (AOD at $440 \mathrm{~nm}$ at 0.16 ) in Fig. 2b we see an agreement between the GARRLiC and the lidar stand-alone absorption 
coefficients at $370 \mathrm{~nm}$, within their uncertainties. The agreement is better at $880 \mathrm{~nm}$.

\subsection{Cyprus campaign}

The mandate of the Cyprus campaign was to investigate the influence of dust on absorption properties. The cases shown here (Fig. 2c) have AODs at $440 \mathrm{~nm}$ of $0.2-0.35$. Due to higher AODs, we achieve a good agreement between GARRLiC, UAV and surface in situ measurements, especially at $370 \mathrm{~nm}$, for the cases on 7 and 21 April (left and right plots, Fig. 2c). On 15 April (middle plots in Fig. 2c) we see disagreement between GARRLiC and in situ UAV measurements, for which we currently investigate the reason(s).

\section{CONCLUSIONS}

In this study we used remote sensing algorithms utilizing the lidar measurements (i.e., lidar standalone algorithm) and the combination of lidar and sun-photometer measurements (i.e., GARRLiC algorithm), along with airborne and surface in situ measurements to characterize the particle aerosol absorption vertical distribution. Data were gathered during three ACTRIS-2 JRA1 campaigns in Germany, Greece and Cyprus in 2015-2016. The lidar stand-alone and the GARRLiC retrievals agree well for a case study in Athens. The remote sensing and airborne in situ measurements were not statistically different in Melpitz, where absorption and extinction coefficients were low. The comparison in Cyprus shows very good agreement between GARRLiC and in situ measurements for most cases investigated.

The difficulties posed in retrieving the absorption profiles are associated with low AODs, the insufficient lidar information in the overlap region and possibly the uncertainties in the airborne in situ sampling. In this line specific actions need to be taken further, as for example to incorporate the lidar near-range signal in the remote sensing retrievals [e.g. 9] that will provide the missing information in the overlap region.

We aim to continue investigating the benefits and improvements brought in by the synergy of remote sensing and in situ techniques for aerosol absorption profile characterization within the framework of the ACTRIS-2 project and its experimental campaigns.

\section{ACKNOWLEDGEMENTS}

The research leading to these results has received funding from the European Union's Horizon 2020 Research and Innovation Programme ACTRIS-2 (grant agreement no. 654109). Elina Giannakaki acknowledges the support of the Academy of Finland (project no. 270108).

\section{References}

[1] Bond, T. C., et al., 2013: Bounding the role of black carbon in the climate system: A scientific assessment, J. Geophys. Res., 118, 5380-5552, doi:10.1002/jgrd.50171.

[2] Wilcox, E. M., et al., 2016: Black carbon solar absorption suppresses turbulence in the atmospheric boundary layer, Proceedings of the National Academy of Sciences, 113 (42), 11794-11799.

[3] Loeb, N. G., and W. Su, 2010: Direct Aerosol Radiative Forcing Uncertainty Based on a Radiative Perturbation Analysis, $J$. Climate, 23, 5288, 2010.

[4] Dubovik, O., and M. D. King, 2000: A flexible inversion algorithm for retrieval of aerosol optical properties from sun and sky radiance measurements, J. Geophys. Res., $\mathbf{1 0 5}, 20,673-20,696$.

[5] Müller, D., et al., 2001: Comprehensive particle characterization from threewavelength Raman-lidar observations, Appl. Opt., 40, 4863-4869.

[6] Lopatin, A., et al., 2013: Enhancement of aerosol characterization using synergy of lidar and sun-photometer coincident observations: the GARRLiC algorithm, Atmos. Meas. Tech., 6, 2065-2088, doi:10.5194/amt-6-2065-2013.

[7] Kebabian, et al., 2007: Optical Extinction Monitor Using CW Cavity Enhanced Detection, Rev. Sci. Instrum., 78: 063102.

[8] Wandinger U. and Ansmann A., 2002: Experimental determination of the lidar overlap profile with Raman lidar, Appl. Opt., 41, 511-514. 
[9] Stachlewska, I.S., et al., 2017: Properties of arctic haze aerosol from lidar observations during iAREA 2015 campaign on Spitsbergen, ILRC28, this issue. 